\title{
The Addiction Profiles of Substance Users with Comorbid Attention Deficit-Hyperactivity Disorder: The Comparison with Substance Users without Comorbid Attention Deficit-Hyperactivity Disorder
}

\author{
Suat Ekinci' ${ }^{1}$, Hanife Uğur Kural ${ }^{2}$, Merve Yalçınay ${ }^{3}$ \\ ${ }^{1}$ Avrupa MYO, Istanbul, Turkey \\ ${ }^{2}$ Fransiz Lape Hospital, The Clinic of Addiction, Istanbul, Turkey \\ ${ }^{3}$ Koç University, Istanbul, Turkey \\ Email: drsuatekinci@gmail.com
}

Received 27 February 2016; accepted 5 April 2016; published 8 April 2016

Copyright (C) 2016 by authors and Scientific Research Publishing Inc.

This work is licensed under the Creative Commons Attribution International License (CC BY). http://creativecommons.org/licenses/by/4.0/

\section{Abstract}

Objective: The aim of this study is to compare the addiction profiles of substance users with comorbid attention deficit-hyperactivity disorder (ADHD) and of those without attention-deficit hyperactivity disorder (ADHD) comorbidity. Method: 100 patients with substance use disorder (SUD) who continued to undergo inpatient treatment during September 2014-August 2015 in Private Balikli Rum Hospital were included in the study. Based on DSM-5 diagnostic criteria, 50 patients who have SUD with ADHD comorbidity were considered as study group, the other 50 patients with only SUD were evaluated as control group. Sociodemographic Data Form, Buss-Perry Aggression Questionnaire (BPAQ), Beck Depression Inventory (BDI), Beck Anxiety Inventory (BAI), Addiction Profile Index (BAPI), and Adult ADHD Self-Report Scale (ASRS ADHD) were given to the patients who participated to the study. Results: It was found that the age of onset for substance use was younger in a statistically significant manner in the patients who had SUD with comorbid ADHD (ADHD-SUD group) than the control group (SUD group) $(t=3.57, p=0.001)$. Regarding to scores in the scales of these two groups, scores of aggression questionnaire (BPAQ) and craving subscale (BAPI) in ADHD-SUD group were significantly higher comparing to SUD group. Conclusion: In this study, it was revealed that the age of onset for substance use was younger in substance users with comorbid ADHD and that the level of aggression and craving was higher again in this group. Crav- 
ing and level of aggression might have negative impacts on the treatment process. Therefore, we believe that it is essential to consider ADHD comorbidity in patients with substance use disorders.

\title{
Keywords
}

\author{
Substance Use, Attention-Deficit, Hyperactivity, Addiction Profile
}

\section{Introduction}

Attention-deficit hyperactivity disorder (ADHD) is a neuropsychiatric disorder in which attention-deficit and hyperactivity symptoms are experienced. It begins in early childhood but its symptoms might continue in adulthood and can cause poor social relationships and academic failure [1] [2].

In lots of studies, it was suggested that mood disorders and substance use disorders (SUD) frequently accompanied in children with ADHD at later ages [3]-[5] and that ADHD is a risk factor in terms of developing SUD [6]-[8].

The studies about ADHD and substance use are more likely to focus on trying to understand whether ADHD is a risk factor for substance use or not and the mechanisms which play a role in developing an addiction behavior for patients with ADHD [9]-[11].

However, it is not examined whether there might be a difference between addiction profiles of patients who have SUD with comorbid ADHD and of those without ADHD comorbidity. Accordingly, we might state that our study aimed at filling this gap in the literature.

The aim of this study: it was intended to compare the addiction profiles of patients who have SUD with ADHD comorbidity and of those who have SUD but without comorbid ADHD. In order to compare these potential differences, Addiction Profile Index (BAPI) was used. Two groups were compared in terms of craving, the effect of substance use on the person's life, and motivation for quitting substance.

\section{Method}

\subsection{Sample}

100 patients with SUD which were in an inpatient treatment during September 2014-August 2015 in Private Balikli Rum Hospital were included in the study. Based on DSM-5 diagnostic criteria, while 50 of them had ADHD comorbidity (ADHD-SUD group), the other 50 did not have (SUD group). The patients who completed 2-week detoxification period and did not have withdrawal symptoms were included in the study. A psychiatrist made a face-to-face interview with patients who had comorbid ADHD. Adult ADHD Self-Report Scale (ASRS ADHD) was used as a subsidiary material for the diagnosis.

Criteria to include in the study: The patients who did not have any withdrawal and psychotic symptoms, were literate, accepted to participate to the study, and signed informed consent were included in the study.

Criteria not to include in the study: The patients who had substance use in the last 2 weeks, had any withdrawal or psychotic symptoms, did not accept to participate to the study or did not sign informed consent were not included in the study.

\subsection{Materials}

Sociodemographic Data Form, Turkish versions of Buss-Perry Aggression Questionnaire (BPAQ), Beck Depression Inventory (BDI), Beck Anxiety Inventory (BAI), Addiction Profile Index (BAPI), and Adult ADHD Self-Report Scale (ASRS ADHD) were given to the participants in the study.

Sociodemographic Data Form: In order to define each participant's age, gender, the level of education, job, the substance which is used, the amount and the way of using, the age of first use, history, and suicidal thoughts, a sociodemographic data form was prepared and given to the participants.

Buss-Perry Aggression Questionnaire (BPAQ): The scale which was developed by Buss and Perry with the aim of assessing the level of aggression and anger consists of 29 items [12]. Participants were asked to rate these 29 items on a Likert-type scale from 0 ("Extremely uncharacteristic") to 4 (“Extremely characteristic"). The va- 
lidity and reliability research of Turkish version was conducted by Demirtaş Madran (2013) [13]. Physical aggression, hostility, anger and verbal aggression are four subscales which are included in this scale.

Beck Depression Inventory (BDI): It was developed in order to assess the risk of depression and the level and severity of depressive symptoms [14]. The inventory consists of 21 items which includes 4 choices. Participants were asked to choose one of 4 choices which was most closely related to them. The Turkish version of this inventory was developed by Hisli [15] and the cut point was found as 17.

Beck Anxiety Inventory (BAI): This inventory developed by Beck and others (1988) [16] is a self-report scale which aims to measure the frequency of anxiety symptoms. It consists of 21 items and these items are rated on a Likert-type scale from 0 ("Not At All”) to 3 ("Severely-it bothered me a lot"). The Turkish version of this inventory was developed by Ulusoy and others (1998) [17].

Addiction Profile Index (BAPI): The scale was developed by Ögel and others (2012) [18] in order to evaluate addiction-related factors. It consists of 37 items. Characteristics of substance use (the substances used and the frequency of use), dependency diagnosis, the effect of substance use on the person's life, craving, and the motivation for quitting substance are 5 subscales of the index. These 37 items are rated on a Likert-type scale from 0 to 4 .

Adult ADHD Self-Report Scale (ASRS ADHD): This scale is one of the scales which was developed by The World Health Organization with the aim of screening for psychological disorders [19]. There are two subscales as "inattention" and "hyperactivity/impulsivity". Participants were expected to rate the frequency of symptoms which they experienced last 6 months on a Likert-type scale from 0 ("Never") to 4 ("Very Often"). The Turkish version of the scale was developed by Doğan and others (2009) [20].

\subsection{Statistical Analysis}

Windows SPSS 13.0 was used for statistical analysis. In order to analyze the difference between categorical variables, chi-square test was conducted. Furthermore, an independent t-test was used with the aim of determining the mean value differences between two groups. In order to evaluate the relationship between scales, Pearson correlation coefficient was applied. $\mathrm{p}<0.05$ was accepted as statistical significance level.

\section{Results}

First of all, we compared these two groups in terms of sociodemographic variables. Participants who were included in the study were male patients. The average age of ADHD-SUD group was $25.56 \pm 6.74$, the year of education was $9.64 \pm 3.41$. The average age of SUD group was $24.98 \pm 8.31$ and the year of education was $9.70 \pm$ 3.61 .

There was not any statistically significant difference between two groups in terms of age and level of education ( $p>0.05$ ). Moreover, in terms of suicidal thoughts, suicide attempts, and history of imprisonment, we could not find a significant difference between two groups $(\mathrm{p}>0.05)$. However, the age of initiation to using substance was younger in ADHD-SUD group than in SUD group and this difference was also statistically significant (Table 1).

Comparing two groups' scores in our scales, they did not differ in terms of BDI, BAI, the effect of substance use on the person's life and motivation subscales in BAPI (Table 2). It was found that the scores of BPAQ and craving subscale of BAPI was higher in ADHD-SUD group than SUD group and that this difference was in a statistically significant level (Table 2).

\section{Discussion}

In this study, we compared the sociodemographic data, the level of aggression, depression, anxiety, and addiction profiles of patients who have SUD with comorbid ADHD and of those without comorbid ADHD.

Comparing these two groups' scale scores, it could not be found any significant difference between BDI and BAI. The findings from the previous studies which tried to compare these two groups in terms of the level of depression and anxiety supported our results [21].

It was revealed that aggression level (BPAQ) in ADHD-SUD group was significantly higher than SUD group.

Thompson et al. (1996) [22] stated that the conduct problems in substance users with ADHD was more likely 
Table 1. Comparing SUD group and ADHD-SUD group in terms of sociodemographic data.

\begin{tabular}{cccc}
\hline & SUD group (n: 50) & ADHD-SUD group (n: 40) & Significance \\
\hline Age $(M \pm$ SD) & $25.56 \pm 6.74$ & $24.98 \pm 8.31$ & $\mathrm{t}=0.790 \mathrm{p}=0.432$ \\
The year of education; & $9.64 \pm 3.41$ & $9.70 \pm 3.61$ & $\mathrm{t}=-0.116 \mathrm{p}=0.908$ \\
Job; Working & $33(66 \%)$ & $23(46 \%)$ & $\chi^{2}=1.500 \mathrm{p}=0.221$ \\
Not working & $17(34 \%)$ & $23(46 \%)$ & \\
Suicidal thoughts: Yes/No & $23 / / 27$ & $22 / 28$ & $\chi^{2}=0.41 \mathrm{p}=0.841$ \\
Suicide attempts: Yes/No & $22 / 28$ & $19 / 31$ & $\chi^{2}=0.372 \mathrm{p}=0.542$ \\
The age of onset of substance use & $20.86 \pm 6.62$ & $17.10 \pm 3.37$ & $\mathrm{t}=3.577 \mathrm{p}=0.001$ \\
\hline
\end{tabular}

$M=$ mean, $\mathrm{SD}=$ standart deviation.

Table 2. Comparing scale scores of two groups.

\begin{tabular}{cccc}
\hline & SUD group $(\mathrm{n}=40)$ & ADHD-SUD group $(\mathrm{n}=40)$ & Significance \\
\cline { 2 - 4 } & $(M \pm \mathrm{SD})$ & $(M \pm \mathrm{SD})$ & \\
\hline Beck Depression Inventory (BDI) & $22.10 \pm 12.06$ & $22.82 \pm 11.76$ & $\mathrm{t}=-0.302 \mathrm{p}=0.763$ \\
Beck Anxiety Inventory (BAI) & $19.56 \pm 15.44$ & $22.72 \pm 15.09$ & $\mathrm{t}=-1.035 \mathrm{p}=0.303$ \\
$\begin{array}{c}\text { Buss-Perry Aggression } \\
\text { Questionnaire (BPAQ) }\end{array}$ & $45.58 \pm 15.21$ & $64.22 \pm 17.905$ & $\mathrm{t}=4.11 \mathrm{p}<0.001^{*}$ \\
BAPI (the effect of the person’s life) & $28.04 \pm 8.90$ & $29.78 \pm 9.74$ & $\mathrm{t}=-0.093 \mathrm{p}=0.353$ \\
BAPİ (craving) & $9.16 \pm 4.12$ & $12.22 \pm 4.72$ & $\mathrm{t}=-3.448 \mathrm{p}<0.001^{*}$ \\
BAPİ (motivation) & $9.74 \pm 3.31$ & $10.56 \pm 2.49$ & $\mathrm{t}=-1.397 \mathrm{p}=0.166$ \\
\hline
\end{tabular}

${ }^{*}=$ Statistically significant in the level of $\mathrm{p}<0.05$.

to accompany this situation and had higher levels of impulsivity and aggression. Additionally, in their studies, Retz et al. (2011) [23] revealed that the levels of impulsivity and aggression was high in substance users with ADHD. Also the difference between the two groups' aggression levels was consistent with previous results.

Finally, these two groups were examined in terms of their addiction profiles. It could not be found any significant difference between ADHD-SUD group and SUD group in terms of the effect of substance use on the person's life and motivation for quitting substance subscales. Due to the fact that there is not any study which tried to examine these two groups regarding the scores of these scales in the literature, we did not have a possibility to compare our results. Galere et al. (2013) [24] described that the patients who had SUD with ADHD symptoms had longer treatment process and briefer remission periods than the patients with only SUD. These findings did not support our results to a certain extent. This might be caused by our sample (the patients in the study underwent inpatient treatment) but we also think that the study should be replicated with different scales and larger sample size in order to evaluate the effect of substance use and motivation for quitting substance much more effectively. Besides, lower validity and reliability coefficients of BAPI motivation subscale might be a factor which caused this result [18].

Moreover, it was found that craving scores of ADHD-SUD group was higher than the scores of SUD group. Because of the fact that there are not any studies which compares the craving of the substance users with comorbid ADHD and of those without ADHD, we did not have a chance to compare our results. We think that it is required our findings to be tested with additional studies in the future.

\section{Conclusion}

In our study, it was revealed that the age of onset for substance use was younger in ADHD-SUD group than SUD group. Regarding the scores of scales, it could not be determined any significant difference between two groups' scores of BDI, BAI, the effect of substance use on the person's life and motivation subscales of BAPI. On the other hand, the level of aggression and craving in ADHD-SUD group was higher than SUD group. It was 
shown in previous studies that the level of aggression and craving being higher might have caused the longer substance use period and briefer remission periods. Hereby, we believe that it is essential to evaluate ADHD comorbidity for patients with substance use disorders routinely.

\section{Limitations of Study}

We have some limitations in our study. Participants included in the study were male patients in an inpatient treatment. Therefore, our results could not be generated to all ADHD patients. Axis I diagnoses were not considered in this study, so the probable influences on addiction profiles could not be examined. Due to the crosssectional structure of our study, our results could not reveal a cause-effect relation. Thus, we need prospective longitudinal studies in order to investigate this relationship.

\section{Disclosure of Interest}

There is no potential conflict of interest of each author. We didn't take any financial support for our study.

\section{References}

[1] Wilens, T.E. (2007) The Nature of the Relationship between Attention-Deficit/Hyperactivity Disorder and Substance Abuse. The Journal of Clinical Psychiatry, 50, 543-553.

[2] Nikolas, M.A. and Burt, S.A. (2010) Genetic and Environmental Influences on ADHD Symptom Dimensions of Inattention and Hyperactivity: A Meta-Analysis. Journal of Abnormal Psychology, 119, 1-17. http://dx.doi.org/10.1037/a0018010

[3] Biederman, J., Petty, C.R., Clarke, A., Lomedico, A. and Faraone, S.V. (2011) Predictors of Persistent ADHD: An 11-Year Follow-Up Study. Journal of Psychiatric Research, 45, 150-156. http://dx.doi.org/10.1016/j.jpsychires.2010.06.009

[4] Katusic, S.K., Barbaresi, W.J., Colligan, R.C., Weaver, A.L., Leibson, C.L. and Jacobsen, S.J. (2005) Psychomotor Stimulant Treatment and Risk for Substance Abuse among Young Adults with a History of Attention-Deficit/Hyperactivity Disorder: A Population-Based, Birth Cohort Study. Journal of Child and Adolescent Psychopharmacology, 15, 764-769. http://dx.doi.org/10.1089/cap.2005.15.764

[5] Ekinci, S., Öncü, B. and Canat, S. (2011) Attention Deficit Hyperactivity Disorders: Comorbidity and Functioning. Anatolian Journal of Psychiatry, 12, 185-191.

[6] Wilens, T.E., Martelon, M.K., Joshi, G., Bateman, C., Fried, R., Petty, C. and Biederman, J. (2011) Does ADHD Predict Substance-Use Disorders? A 10-Year Follow-Up Study of Young Adults with ADHD. Journal of the American Academy of Child \& Adolescent Psychiatry, 50, 543-553. http://dx.doi.org/10.1016/j.jaac.2011.01.021

[7] Milberger, S., Biederman, J., Faraone, S.V., Chen, L. and Jones, J. (1997) ADHD Is Associated with Early Initiation of Cigarette Smoking in Children and Adolescents. Journal of the American Academy of Child \& Adolescent Psychiatry, 36, 37-44. http://dx.doi.org/10.1097/00004583-199701000-00015

[8] Biederman, J., Wilens, T., Mick, E., Faraone, S.V., Weber, W., Curtis, S., Thornell, A., Pfister, K., Jetton, J.G. and Soriano, J. (1997) Is ADHD a Risk Factor for Psychoactive Substance Use Disorders? Findings from a Four-Year Prospective Follow-Up Study. Journal of the American Academy of Child \& Adolescent Psychiatry, 36, 21-29. http://dx.doi.org/10.1097/00004583-199701000-00013

[9] Sher, K.J. and Trull, T.J. (1994) Personality and Disinhibitory Psychopathology: Alcoholism and Antisocial Personality Disorder. Journal of Abnormal Psychology, 103, 92-102. http://dx.doi.org/10.1037/0021-843X.103.1.92

[10] Tarter, R.E., Vanyukov, M., Giancola, P., Dawes, M., Blackson, T., Mezzich, A. and Clark, D.B. (1999) Etiology of Early Age Onset Sub-Stance Use Disorder. A Maturational Perspective. Developmental Psychobiology, 11, 657-683. http://dx.doi.org/10.1017/S0954579499002266

[11] Biederman, J., Faraone, S.V., Keenan, K., Benjamin, J., Krifcher, B., Moore, C., et al. (1992) Further Evidence for Family-Genetic Risk Factors in Attention Deficit Hyperactivity Disorder (ADHD): Patterns of Comorbidity in Probands and Relatives in Psychiatrically and Pediatrically Referred Samples. Archives of General Psychiatry, 49, 728-738. http://dx.doi.org/10.1001/archpsyc.1992.01820090056010

[12] Buss, A.H. and Perry, M. (1992) The Aggression Questionnaire. Journal of Personality and Social Psychology, 63, 452-459. http://dx.doi.org/10.1037/0022-3514.63.3.452

[13] Demirtaş Madran, H.A. (2013) Buss-Perry Saldırganlık Ölçeği’nin Türkçe formunun geçerlik ve güvenirlik çalışması. Turkish Journal of Psychiatry, 24, 1-6.

[14] Beck, A.T. (1961) An Inventory for Measuring Depression. Archives of General Psychiatry, 4, 561-571. 
http://dx.doi.org/10.1001/archpsyc.1961.01710120031004

[15] Hisli, N. (1989) Beck Depresyon Envanterinin üniversite öğrencileri için geçerliği, güvenirliği. Psikoloji Dergisi, 7, 3-13.

[16] Beck, A.T., Epstein, N., Brown, G. and Steer, R.A. (1988) An Inventory for Measuring Clinical Anxiety: Psychometric Properties. Journal of Consulting and Clinical Psychology, 56, 893-897. http://dx.doi.org/10.1037/0022-006X.56.6.893

[17] Ulusoy, M., Şahin, N. and Erkman, H. (1998) Turkish Version of the Beck Anxiety Inventory: Psychometric Properties. Journal of Cognitive Psychotherapy, 12, 163-172.

[18] Ögel, K.Ö., Evren, C., Karadağ, F. and Tamar Gürol, D. (2012) Bağımlılık Profil İndeksi'nin (BAPİ) geliştirilmesi, geçerlik ve güvenilirliği. Turkish Journal of Psychiatry, 23, 1-10.

[19] Kessler, R.C., Adler, L., Ames, M., Demler, O., Faraone, S., Hiripi, E., et al. (2005) The World Health Organization Adult ADHD Self-Report Scale (ASRS): A Short Screening Scale for Use in the General Population. Psychological Medicine, 35, 245-256. http://dx.doi.org/10.1017/S0033291704002892

[20] Doğan, S., Öncü, B., Varol-Saraçoğlu, G. and Küçükgörücü, S. (2009) Erişkin Dikkat Eksikliğj Hiperaktivite Bozukluğu Kendi Bildirim Ölçeği (ASRS-v1.1): Türkçe formunun geçerlilik ve güvenilirliği. Anatolian Journal of Psychiatry, 10, 77-87.

[21] Biederman, J., Wilens, T., Mick, E., Milberger, S., Sepencer, T.J. and Faraone, S.V. (1995) Psychoactive Substance Use Disorders in Adults with Attention Deficit Hyperactivity Disorder (ADHD): Effects of ADHD and Psychiatric Comorbidity. American Journal of Psychiatry, 152, 1652-1658. http://dx.doi.org/10.1176/ajp.152.11.1652

[22] Thompson, L.L., Riggs, P.D., Mikulich, S.K. and Crowley, T.J. (1996) Contribution of ADHD Symptoms to Substance Problems and Delinquency in Conduct-Disordered Adolescents. Journal of Abnormal Child Psychology, 24, 325-347. http://dx.doi.org/10.1007/BF01441634

[23] Retz, W. and Rösler, M. (2009) The Relation of ADHD and Violent Aggression: What Can We Learn from Epidemiological and Genetic Studies? International Journal of Law and Psychiatry, 32, 235-243.

[24] Galéra, C., Pingault, J., Fombonne, E., Michel, G., Legarde, E., Bouvard, M. and Melchior, M. (2013) Attention Problems in Childhood and Adult Substance Use. The Journal of Pediatrics, 163, 1677-1683. http://dx.doi.org/10.1016/j.jpeds.2013.07.008 